\title{
Modelling a heater experiment for radioactive waste disposal
}

Thanh Son Nguyen P. Eng., PhD

Geoscience Technical Specialist, Canadian Nuclear Safety Commission,

Ottawa, ON, Canada (corresponding author: son.nguyen@cnsc-ccsn.gc.ca)

Zhenze Li PhD

Consultant, Canadian Nuclear Safety Commission, Ottawa, ON, Canada
Benoit Garitte CEng

Project Manager, Geomechanics, Nationale Genossenschaft für die Lagerung Radioaktiver Abfälle, Wettingen, Switzerland

Jean Dominique Barnichon PhD

Laboratory Head, Institut de Radioprotection et de Sûreté Nucléaire, Fontenay-aux-Roses, France

This paper presents the Canadian Nuclear Safety Commission's modelling of coupled thermal, hydraulic and mechanical (THM) processes and their influence on the performance of the engineered barrier system (EBS) and the host rock. The coupled THM processes were monitored during a heater experiment called HE-E, performed in an Opalinus Clay formation at the Mont Terri Rock Laboratory in Switzerland. The HE-E experimental set-up consisted of two EBS sections emplaced in an existing tunnel of the Underground Rock Laboratory. This paper focuses on the model development, parametric analysis, model calibration and verification with the field test data. The influence of THM processes on the EBS and host rock performance and the implications on the design and safety assessment of geological disposal repository systems are discussed.

\section{Notation}

C stiffness tensor for the porous media

C specific heat capacity of the porous medium $(\mathrm{J} /(\mathrm{kg} \mathrm{K}))$

$C_{\mathrm{m}} \quad$ specific moisture capacity given by the slope of moisture variation with suction $\left(\mathrm{Pa}^{-1}\right)$

$D_{\text {atm }}$ free diffusion coefficient of water vapour in the atmosphere $\left(\mathrm{m}^{2} / \mathrm{s}\right)$

$D_{\mathrm{pv}} \quad$ diffusivity of water vapour under pressure gradient $\left(\mathrm{m}^{2} /(\mathrm{s} \mathrm{Pa})\right)$

$D_{\mathrm{Tv}} \quad$ diffusivity of water vapour under thermal gradient $\left(\mathrm{m}^{2} /(\mathrm{s} \mathrm{K})\right)$

$D_{\mathrm{v}} \quad$ vapour diffusion coefficient $\left(\mathrm{m}^{2} / \mathrm{s}\right)$

$\mathrm{d} T$ temperature change $(\mathrm{K})$

E Young's modulus (Pa)

g acceleration of gravity $\left(\mathrm{m} / \mathrm{s}^{2}\right)$

I $\quad\{1 / 3,1 / 3,1 / 3,0,0,0\}$

$\boldsymbol{k}$ permeability tensor $\left(\mathrm{m}^{2}\right)$

$k_{\mathrm{s}} \quad$ intrinsic permeability at full saturation $\left(\mathrm{m}^{2}\right)$

$l \quad$ another constant of the van Genuchten model for water retention characteristics

M molecular weight of water

$n$ porosity

$p \quad$ pore pressure $(\mathrm{Pa})$

$p_{\mathrm{c}} \quad$ matric suction $(\mathrm{Pa})$

Q heat source term $\left(\mathrm{W} / \mathrm{m}^{3}\right)$

$q_{\mathrm{v}} \quad$ rate of vapour diffusion $\left(\mathrm{kg} / \mathrm{s} / \mathrm{m}^{2}\right)$

$R \quad$ ideal gas constant

$R_{\mathrm{H}} \quad$ relative humidity

$R_{\mathrm{V}} \quad$ gas constant for vapour

$S \quad$ storage term defined by $S=n \chi_{\mathrm{f}}+(1-n) \chi_{\mathrm{s}}+$ $\left(n \rho_{\mathrm{a}} \chi_{\mathrm{a}} / \rho_{1} S_{\mathrm{e}}\right)\left(\mathrm{Pa}^{-1}\right)$

$S_{\mathrm{e}} \quad$ effective liquid water saturation

$T$ temperature (K)

$T_{\mathrm{x}} \quad$ thermal expansion coefficient $\left(\mathrm{K}^{-1}\right)$ time (s)

Poisson ratio

Biot's coefficient

$\alpha_{\mathrm{w}} \quad$ constant of the van Genuchten model for water retention characteristics $\left(\mathrm{m}^{-1}\right)$

$\beta \quad$ coefficient of volumetric thermal expansion for the solid skeleton $\left(\mathrm{K}^{-1}\right)$

$\beta_{\mathrm{s}} \quad$ coefficient of thermal expansion of the grains $\left(\mathrm{K}^{-1}\right)$

$\beta_{\mathrm{w}} \quad$ coefficient of thermal expansion of the pore fluid $\left(\mathrm{K}^{-1}\right)$

$\varepsilon \quad$ strain tensor

$\varepsilon_{\mathrm{v}} \quad$ volumetric strain

$\kappa_{\mathrm{T}} \quad$ heat conductivity of the porous medium $(\mathrm{W} /(\mathrm{m} \mathrm{K}))$

$\mu \quad$ dynamic viscosity of the pore fluid $(\mathrm{kg} /(\mathrm{m} \mathrm{s}))$

$\rho_{\mathrm{a}} \quad$ water vapour density $\left(\mathrm{kg} / \mathrm{m}^{3}\right)$

$\rho_{\mathrm{b}} \quad$ bulk density of the porous medium $\left(\mathrm{kg} / \mathrm{m}^{3}\right)$

$\rho_{\mathrm{l}} \quad$ liquid water density $\left(\mathrm{kg} / \mathrm{m}^{3}\right)$

$\rho_{\mathrm{v}} \quad$ vapour density

$\rho_{\mathrm{vs}} \quad$ saturated vapour density

$\sigma \quad$ total stress $(\mathrm{Pa})$

$\sigma^{\prime} \quad$ effective stress $(\mathrm{Pa})$

$\tau \quad$ tortuosity factor

$\chi_{\mathrm{a}} \quad$ water vapour compressibility defined by $\chi_{\mathrm{a}}=\left(M / \rho_{\mathrm{a}} R T\right)$ $\left(\mathrm{Pa}^{-1}\right)$

$\chi_{\mathrm{f}} \quad$ fluid compressibility $\left(\mathrm{Pa}^{-1}\right)$

$\chi_{\mathrm{s}} \quad$ solid compressibility $\left(\mathrm{Pa}^{-1}\right)$

\section{Introduction}

Many countries that use nuclear power for the production of electricity, including Canada, are currently considering the disposal of radioactive wastes in deep geological formations. Geological disposal relies on multiple barriers - for example, engineered clay barriers and thick layers of natural sedimentary rocks - to contain and isolate the radioactive wastes for very long periods of time. The long-term performance of those barriers is crucial to the safety 
of the geological disposal system and is therefore investigated collaboratively by interdisciplinary researchers.

Experiments on thermal-hydraulic-mechanical (THM)-coupled processes have been reported since the 1990s, including small-scale laboratory column tests (Chijimatsu et al., 2000; Nguyen and Selvadurai, 1997; Pintado et al., 2011; Schanz et al., 2013; Selvadurai, 1996) and large-scale in situ mock-up tests (Gens et al., 2009; Villar and Lloret, 2004). The heating within the clay barrier is always coupled with the infiltration of water to mimic the inflow of groundwater from the surrounding host rock, resulting in a nonlinear evolution of the mechanical response of both the clay barrier and the host rock (Holton et al., 2012; Thomas et al., 2014). Multiphase flow in compacted bentonite has been the focus of intensive experimental investigations focusing on the water retention characteristics, the intrinsic permeability and the relative permeability (Chijimatsu et al., 2000; Cho et al., 2009; Pintado et al., 2011; Schanz et al., 2013; Selvadurai, 1996, 2002). The primary parameters that are monitored generally include temperature, relative humidity/suction, water content, pore pressure and stress. Differences among these experimental studies mainly involve the heater size and the barrier thickness, as well as the type of clay minerals, the host rock and the salinity and composition of the infiltrated water. In the meantime, vapour transport in bentonite has been found to be predominant for water movement under thermal gradients (Gens et al., 2009; Hökmark et al., 2007; Kröhn, 2005, 2010). The present study deals with the HE-E heating test performed at the Mont Terri Rock Laboratory located in an argillaceous rock formation in Switzerland. Preliminary studies on the same set of data showed significant discrepancy between modelling and experimental results with respect to temperature and moisture evolutions (Gaus et al., 2014). In order to improve the simulation of the moisture movement in the clay buffer, a thermal enhancing factor was considered in the present study to reflect the enhancement of thermal water vapour diffusion in porous media (Cass et al., 1984). The introduction of this enhancement factor, as well as its calibration with a laboratory column experiment, proved to be critical to the authors' success in achieving better agreement with the experimental observations in the HE-E test.

The modelling of THM-coupled processes has been developed simultaneously with the experimental studies. A recent study by Chijimatsu et al. (2009) compared some of the most up-to-date THM-coupled models, describing both the relevant governing equations and the modelling results against the same set of test data. Owing to the complexity in both the physics and the characterisation of the material properties, different assumptions in the conceptual model, constitutive relationship and choice of parameters contribute to the discrepancy in the modelling output (Rutqvist et al., 2005a, 2005b). Of all the primary variables, temperature proved to be the easiest parameter to predict since it was conduction dominated owing to the low permeability of the material under consideration and it was not significantly impacted by HM coupling (Rutqvist et al., 2005b). The interaction between the clay barrier and fractured granitic rocks has been well investigated (Holton et al., 2012; Rutqvist et al., 2005b; Thomas et al., 2014; Zheng et al., 2010). The hydraulic conductivities of fractured rocks can be several orders of magnitude higher than those of intact rocks (Massart and Selvadurai, 2014; Selvadurai, 2002). Therefore, in the former case, the resaturation of the buffer can be much shorter (Rutqvist et al., 2005b). The resaturation of the buffer results in the swelling of the clay mineral, leading to: a significant increase in confining stress on the tunnel wall; a significant decline in fracture permeability (Selvadurai, 2015); and an increase in pore pressure in the host rock (Rutqvist et al., 2014). Fewer studies are available for clay barrier/rock interaction in argillaceous rock, such as the one being explored in the present work. A recent such study by Rutqvist et al. (2014) showed that this issue is unique in certain respects. In particular, the low permeability of the argillaceous rock and its inherent anisotropy due to bedding can greatly influence the THM evolution of the clay barrier and, in particular, the time for its resaturation.

The Canadian Nuclear Safety Commission (CNSC) is the nuclear regulator in Canada and will ultimately be responsible for the approval and licensing of current and future geological repositories proposed in Canada. CNSC licensing decisions must be based on science-based arguments on the safety of the proposed facilities. To develop and maintain its expertise, the CNSC participates in collaborative projects with international partners in multidisciplinary projects such as the ones described earlier. This paper presents an example of such collaborative efforts. It describes the development of a mathematical model to simulate the coupled THM processes in a heating experiment called HE-E performed in an argillaceous rock formation, known as Opalinus Clay, at the Mont Terri Rock Laboratory in Switzerland. Field data from the HE-E experiment recorded over a period of 3 years were compared with the results of the THM-coupled model developed by the authors. A long-term simulation (11000 years) was also conducted to simulate the gradual progress of the resaturation of the clay barriers with groundwater permeating from the host rock.

\section{Description of the HE-E experiment and the laboratory column tests}

The HE-E experiment was performed in a microtunnel of the Mont Terri Rock Laboratory (Figure 1). In the HE-E experiment, two sections were isolated in a microtunnel previously excavated in Opalinus Clay. Bentonite pellets (B) were emplaced in one section and sand/bentonite $(\mathrm{S} / \mathrm{B})$ mixture in the other. Electric heaters were enclosed in each section. The heaters were subsequently powered at controlled temperature or controlled power output. The experiment was designed to simulate the heat released from waste canisters and its impact on moisture, temperature, deformation and pore pressure evolution inside the engineered barrier system (EBS) and across the EBS-host rock interface. Those parameters were continuously monitored during the experiment.

The design parameters, as-built information, geoscientific data and preliminary monitoring data of the HE-E experiment were reported by Gaus et al. (2014). The complete set of experimental 


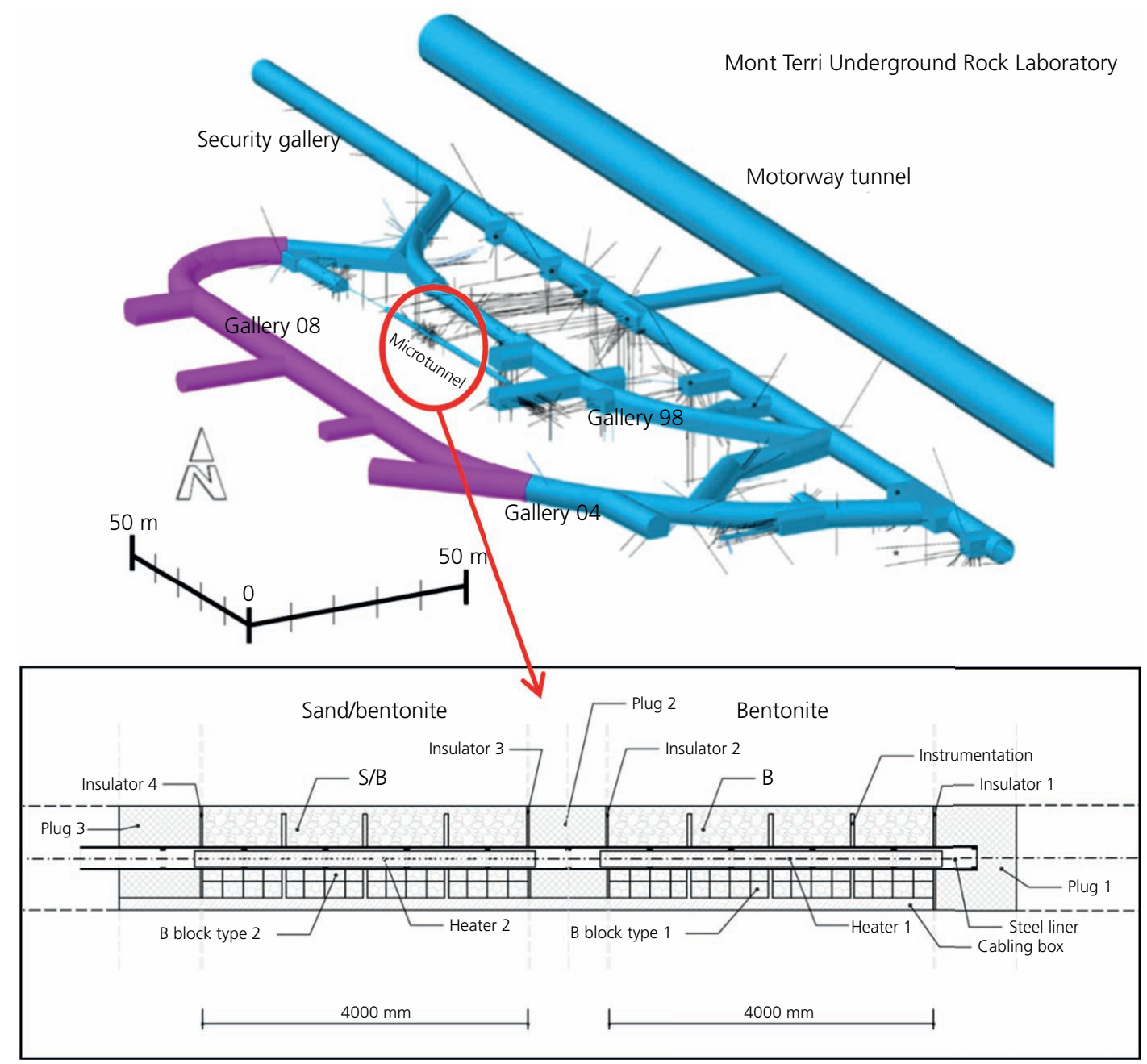

Figure 1. General set-up of the HE-E heating experiment at the Mont Terri Rock Laboratory

results was provided by Nationale Genossenschaft für die Lagerung Radioaktiver Abfälle (Switzerland), through the international collaborative project Decovalex (2017) that aims to develop and validate coupled models for the safety and performance assessment of deep geological repositories for nuclear wastes.

Prior to the HE-E experiment, two small-scale laboratory column tests (Villar et al., 2012) were conducted to determine the THMcoupled behaviour of the EBS used in the HE-E field test (Figure 2). Bs were used in one test, and an S/B mixture was used in the other. The Bs and S/B mixture had the same predetermined optimum water content and target density as the material used in the HE-E experiment. The columns had a height of $50 \mathrm{~cm}$ and a diameter of $7 \mathrm{~cm}$. The EBS material was compacted into a Teflon column, which was wrapped with thermal insulating materials. Three integrated sensors capable of measuring both the relative humidity and temperature were installed at different depths to monitor the evolution of temperature and relative humidity. Heat was supplied at the bottom of the column with fixed temperatures of $100^{\circ} \mathrm{C}(t<2500 \mathrm{~h})$ and $140^{\circ} \mathrm{C}(t>2500 \mathrm{~h})$ while constant temperature (ambient temperature at around $20-21^{\circ} \mathrm{C}$ ) was maintained at the top. The temperature of the heater is uniform in the cross-section. The columns were laterally insulated with a $5 \mathrm{~mm}$ thick dense foam, which was changed to a $30 \mathrm{~mm}$ thick insulation wool after $1566 \mathrm{~h}$, and again modified after $1666 \mathrm{~h}$ by adding a $25 \mathrm{~mm}$ thick Isover BT-LV insulation for a length of $8 \mathrm{~cm}$ from the bottom of the column.

\section{Theories on THM-coupled models}

\section{Conceptualisation}

Figure 3 shows the authors' conceptualisation of the physical processes that take place in the HE-E experiment. First, it is assumed that both the EBS and the host rock can be idealised as porous media, where the pores are filled with liquid water, water vapour and air. At the start of heating, the rock is saturated with liquid water, except for a thin zone around the emplacement tunnel where ventilation partially desaturates the pores. The EBS was emplaced in an unsaturated state - that is, the pores are filled 
Environmental Geotechnics

Volume 6 Issue EG2
Modelling a heater experiment for

radioactive waste disposal

Nguyen, Li, Garitte and Barnichon

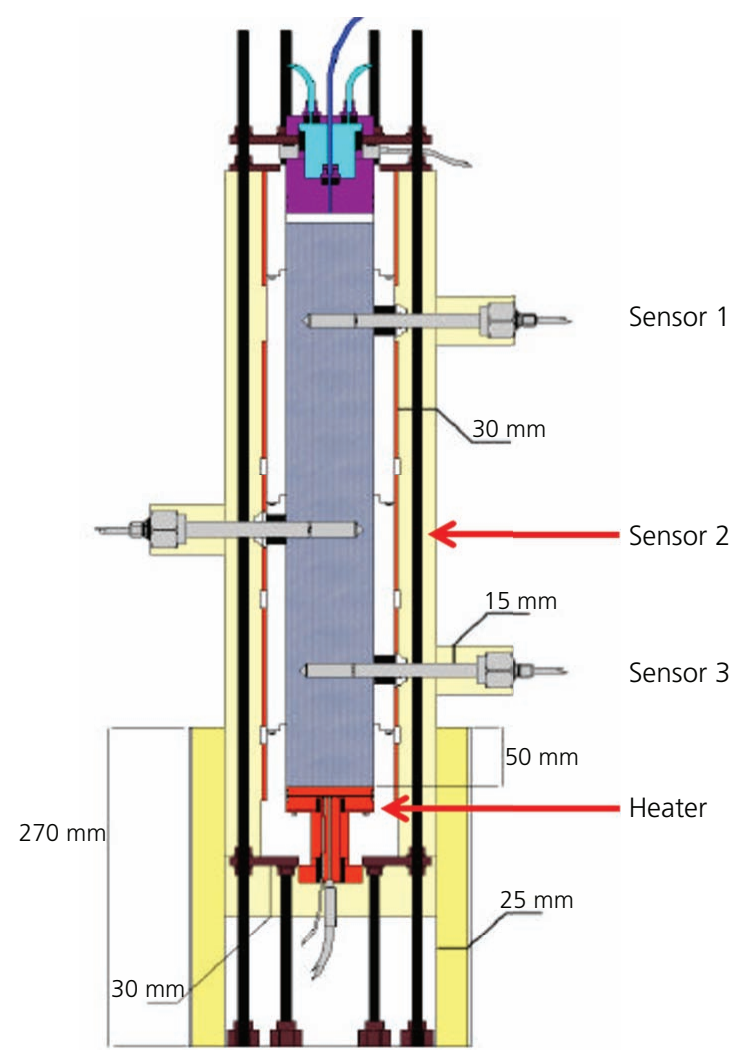

Figure 2. Laboratory column test on the bentonite-based EBS material with relative location of sensors for temperature and relative humidity

with a mixture of liquid water, water vapour and air. When the heaters are powered, a heat flux is induced outwards, resulting in an increase in temperature in both the EBS and the rock, with higher temperatures closer to the heater. The increase in temperature results in thermal stress and strain in both media. Additionally, it induces the evaporation of liquid water near the heaters, which migrates outwards and condenses at lower temperatures. In the EBS, resaturation also induces swelling. The host rock is mainly saturated; therefore, pore water flows from regions of higher to lower pore pressure. Prior to heating, flow is towards the emplacement tunnel. After heating, the pore pressure increases near the periphery of the emplacement tunnel, due to the differential in the thermal expansion between the pore water and the solid skeleton. This would induce a transient outward flow, until the thermally induced pore pressure dissipates.

\section{Coupled governing equations}

The mathematical model was developed based on the previous conceptualisation within the framework of the classical theory of poromechanics, using an approach similar to that of Nguyen and Selvadurai (1995), Rutqvist et al. (2001) and Nguyen et al. (2005). The fundamental principles that were invoked in order to develop the governing equations of coupled THM processes were conservation of mass, conservation of energy and

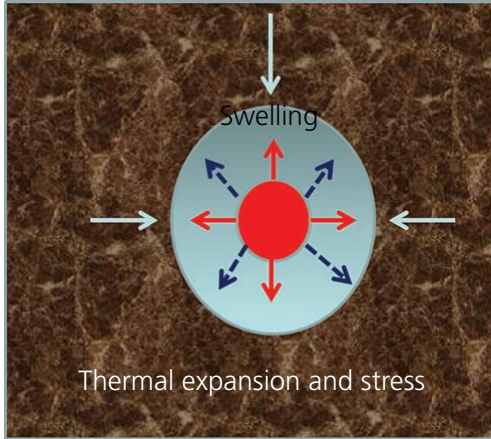

$\longrightarrow$ Heat flux

Evaporation, $\rightarrow$ condensation and vapour diffusion

Water flow

Figure 3. Conceptualisation of physical processes in the HE-E experiment

conservation of momentum. In addition, the following main assumptions were made.

(a) The geological medium is conceptualised as a porous medium.

(b) Only heat is considered in the energy balance equation.

Thermal equilibrium is assumed between the solid and liquid phases. Furthermore, heat transfer occurs only by conduction.

(c) The water in the pores can exist in a liquid and/or gaseous (vapour) phase. It is assumed that water vapour pressure remains constant at atmospheric pressure.

(d) In the EBS, the flow of liquid water is by advection and is assumed to follow Darcy's law, while the vapour flow is by diffusion. The rock is saturated or nearly saturated; therefore, vapour flow is neglected in the rock.

(e) A modified Biot's effective stress principle is assumed

1. $\sigma=\sigma^{\prime}+\chi p$

where

$$
\chi=\alpha \quad \text { if } \quad p \geq 0
$$

2. $\chi=0$ if $p<0$

( $f$ ) The storage term for water vapour is negligible compared to that of liquid water because the density of water vapour is very small compared to that of liquid water, by six orders of magnitude (Rutqvist et al. 2001).

The resulting governing equations of heat, mass and momentum conservation (or equation of equilibrium, since dynamic effects are neglected) are as follows

- equation of heat conservation

3. $\rho_{\mathrm{b}} C \frac{\partial T}{\partial t}=\nabla\left(\kappa_{\mathrm{T}} \nabla T\right)+Q$ 
- equation of water mass conservation for the rock

$$
\begin{gathered}
\rho_{1}\left(\frac{C_{\mathrm{m}}}{\rho_{\mathrm{l}} \boldsymbol{g}}+S_{\mathrm{e}} S\right) \frac{\partial p}{\partial t}+\nabla \frac{\boldsymbol{k} \rho_{\mathrm{l}}}{\mu} \nabla p \\
=\alpha \rho_{\mathrm{l}} S_{\mathrm{e}} \frac{\partial \varepsilon_{\mathrm{v}}}{\partial t} \\
\quad+\rho_{\mathrm{l}} S_{\mathrm{e}}\left[\beta(1-\alpha)-n \beta_{\mathrm{w}}-(1-n) \beta_{\mathrm{s}}\right] \frac{\partial T}{\partial t}
\end{gathered}
$$

- equation of water mass conservation for the EBS

$$
\begin{aligned}
\rho_{1}\left(\frac{C_{\mathrm{m}}}{\rho_{\mathrm{l}} \boldsymbol{g}}+S_{\mathrm{e}} S\right) \frac{\partial p}{\partial t}+\nabla \frac{\boldsymbol{k} \rho_{\mathrm{l}}}{\mu} \nabla p \\
=\alpha \rho_{1} S_{\mathrm{e}} \frac{\partial \varepsilon_{\mathrm{v}}}{\partial t}-\nabla \rho_{1}\left(D_{\mathrm{pv}} \nabla p+D_{\mathrm{Tv}} \nabla T\right) \\
\quad+\rho_{\mathrm{l}} S_{\mathrm{e}}\left[\beta(1-\alpha)-n \beta_{\mathrm{w}}-(1-n) \beta_{\mathrm{s}}\right] \frac{\partial T}{\partial t}
\end{aligned}
$$

- equation of equilibrium in the rock

$$
\text { 6. } \boldsymbol{C}: \nabla(\boldsymbol{\varepsilon}-\beta \mathrm{d} T \mathbf{I})+\alpha \nabla p=0
$$

n equation of equilibrium in the EBS

$$
\text { 7. } \boldsymbol{C}: \nabla(\boldsymbol{\varepsilon}-\beta \mathrm{d} T \mathbf{I})=0
$$

In the present work, both the host rock and EBS are assumed to be elastic. The properties of the host rock in terms of thermal conductivity, permeability and elasticity matrix are, however, assumed to be transversely isotropic, with principal directions parallel and perpendicular to the bedding orientation.

\section{Vapour diffusion in the EBS}

The derivation of the diffusivity coefficients in Equation 5 is provided in the following. It is assumed that in the EBS, liquid water migrates by advection and obeys Darcy's law, while water vapour migrates by diffusion. The rate of vapour diffusion is given by Philip and De Vries (1957) as

\section{8. $q_{\mathrm{v}}=-D_{\mathrm{v}} \nabla \rho_{\mathrm{v}}$}

with the vapour diffusion coefficient $D_{\mathrm{v}}$ expressed as

9. $D_{\mathrm{v}}=-D_{\mathrm{atm}} \tau n\left(1-S_{\mathrm{e}}\right)$

By differentiation, the gradient of vapour density could be decomposed into two components that are dependent on the gradients of pore pressure and temperature as
10. $\nabla \rho_{\mathrm{v}}=\nabla\left(\rho_{\mathrm{vs}} \mathrm{e}^{p_{\mathrm{c}} / \rho_{\mathrm{l}} R_{\mathrm{v}} T}\right)$

Philip and De Vries (1957) expressed the vapour flux in the form of

11. $q_{\mathrm{v}}=-\rho_{\mathrm{l}}\left(D_{\mathrm{pv}} \nabla p+D_{\mathrm{Tv}} \nabla T\right)$

where the diffusivity coefficients $D_{\mathrm{pv}}$ and $D_{\mathrm{Tv}}$ are expressed as

12. $D_{\mathrm{pv}}=D_{\mathrm{v}} \rho_{\mathrm{v}} / \rho_{1}^{2} R_{\mathrm{v}} T$

13.

$$
D_{\mathrm{Tv}}=\frac{f_{\mathrm{Tv}} D_{\mathrm{v}}\left[R_{\mathrm{H}}\left(\mathrm{d} \rho_{\mathrm{vs}} / \mathrm{d} T\right)-\left(p_{\mathrm{c}} \rho_{\mathrm{v}} / \rho_{\mathrm{l}} R_{\mathrm{v}} T^{2}\right)\right]}{\rho_{\mathrm{l}}}
$$

In Equation $13, R_{\mathrm{H}}$ is the relative humidity and $f_{\mathrm{Tv}}$ is a thermal enhancing factor for vapour diffusion (Rutqvist et al., 2001).

\section{Parameters, numerical models and modelling approach}

\section{Fundamental parameters}

\section{EBS materials}

Villar et al. (2012) reported the details of the EBS materials that were tested in the HE-E heating test. In one section of the HE-E experiment, an $\mathrm{S} / \mathrm{B}$ mix at a ratio of $\mathrm{S}: \mathrm{B}=65: 35$ is emplaced together with bentonite blocks. The bentonite used in the S/B mix is a natural sodium bentonite from Wyoming (MX-80). Both the quartz sand and sodium bentonite have the same grain size distribution in the range of $0 \cdot 5-1.8 \mathrm{~mm}$, which was obtained by crushing and sieving from the qualified raw material. Water content was $13 \%$ for the bentonite and $0.05 \%$ for the sand, giving an equivalent water content of the mixture in the range of $4 \%$. Granular B and bentonite blocks are used in the other section of the test; the sodium bentonite is also from Wyoming. Once emplaced, its water content was $5 \cdot 9 \%$ and the dry average density was $1460 \mathrm{~kg} / \mathrm{m}^{3}$.

Retention curves and thermal conductivity

Figure 4(a) shows the water retention characteristics of B, S/B and Opalinus Clay. Brooks-Corey and van Genuchten models (Villar et al., 2012) are used to fit the experimental characteristics. Figure 4(b) shows the non-linear thermal conductivities of the two EBS materials - that is, S/B and B. Figure 4(c) shows the nonlinear $S_{\mathrm{e}}$-dependent thermal diffusion enhancement factor for EBS materials due to the localised thermal gradient enhancement of vapour in porous media (Philip and De Vries, 1957). Other fundamental parameters are listed in Table 1. The input parameters were estimated from a combination of the published data as cited earlier and the calibration of the laboratory column tests is reported next. 


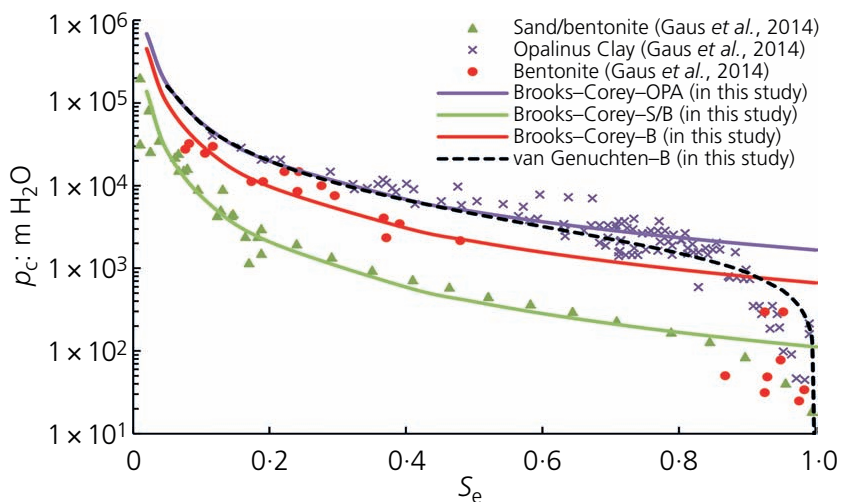

(a)

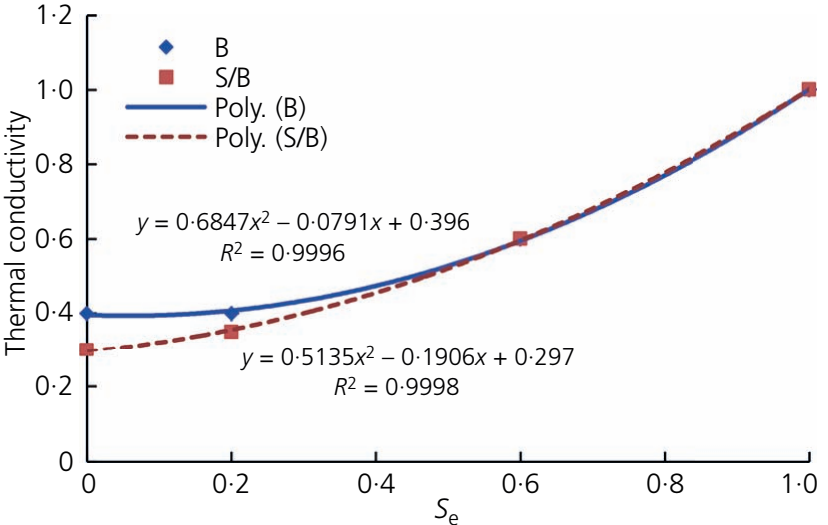

(b)

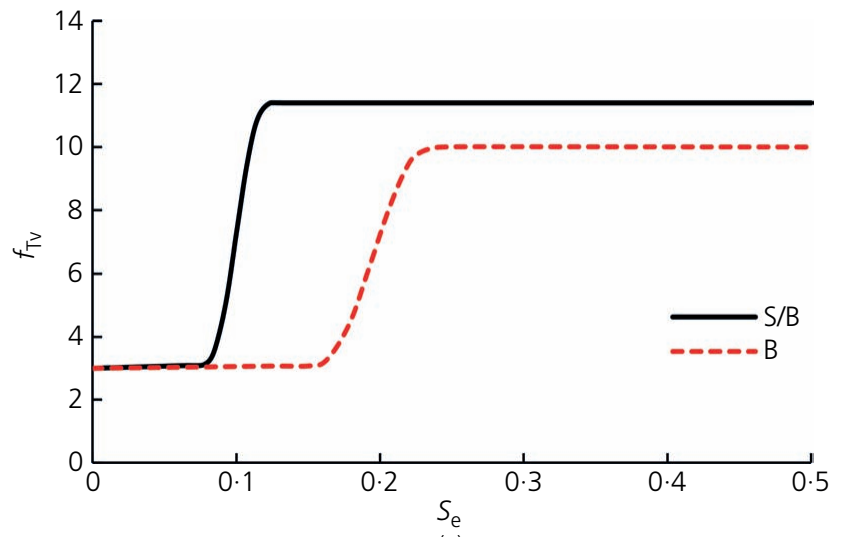

(c)

Figure 4. Dependence of various parameters with saturation degree for S/B and B: (a) matric suction, (b) thermal conductivity and (c) diffusivity enhancement factor $f_{\mathrm{TV}}$

\section{Calibration of column heating tests}

Finite-element models were developed for the column heating tests for both S/B and B columns. The governing equations, with boundary and initial conditions as described next, were numerically solved using the commercial Comsol multiphysics finite-element software (version 4.3b). Boundary conditions included constant temperatures at both the bottom and top boundaries and a variable heat leakage flux for the side-wall to represent the change in insulation. Detailed experimental parameters for this series of column tests can be found in a separate paper (Villar et al., 2012). The initial conditions for temperature, moisture content and porosity were set as determined by experiment. Figures 5(a)-5(d) show the comparison between modelling results of temperature and relative humidity $\left(R_{\mathrm{H}}\right)$ and the monitored data of the laboratory-scale column tests. Evolutions of both temperature and $R_{\mathrm{H}}$ with time are found to be consistent with the experimental observations. Significant temperature shift takes place in the soils column immediately when the source temperature of the heater is increased. The fluctuation is more obvious in regions closer to the heater as a result of the heat diffusion. The moisture movement is dependent on both temperature and suction gradient. As a result, the peaks in $R_{\mathrm{H}}$ of sensor 3 as shown in Figures 5(b) and 5(d) are mainly due to temperature shift, which, although increasing temporarily in magnitude, diminishes quickly due to the re-equilibration of the matric suction. For zones far away from the heating source (i.e. sensor 1), $R_{\mathrm{H}}$ is found to climb up continuously, which is attributed to two factors, $(a)$ the impermeable boundary condition and $(b)$ the cooler heat sink of the top end. The discrepancy in $R_{\mathrm{H}}$ for sensor 1 of $\mathrm{S} / \mathrm{B}$ column is caused by experimentally introduced disturbance to the top boundary, where water leakage into the soil column has happened unintentionally for a short period of time. As for column B, which has maintained ideal boundary conditions throughout the test, the modelling gives a perfect match to the observed $R_{\mathrm{H}}$ values. The authors' model demonstrates very good agreement with test data, suggesting a successful model calibration. The model constants are thus regarded as representative of the tested samples. Due to the high degree of similarity in the EBS preparation process, these parameters are further applied to the simulation of the field case.

\section{Finite-element model for the HE-E experiment}

A three-dimensional (3D) finite-element model (FEM) was developed for the HE-E experiment, assuming symmetry along the vertical plane running through the axis of the microtunnel. The main features of the FEM are shown in Figure 6. The cross-sectional 
Table 1. Fundamental parameters for the numerical simulation

\begin{tabular}{|c|c|c|c|c|c|c|}
\hline Parameter & S/B & B & Opalinus Clay & B block & Plug & EDZ \\
\hline \multicolumn{7}{|l|}{ Physical properties } \\
\hline Grain density: $\mathrm{kg} / \mathrm{m}^{3}$ & 2546 & 2700 & 2700 & 2700 & 2650 & 2700 \\
\hline Dry density: $\mathrm{kg} / \mathrm{m}^{3}$ & 1383 & 1513 & 2330 & 1806 & - & 2330 \\
\hline Porosity & 0.47 & 0.45 & $0 \cdot 12$ & 0.33 & $0 \cdot 15$ & $0 \cdot 14$ \\
\hline Initial saturation (suction): MPa & $0 \cdot 11(122)$ & $0.2(93 \cdot 7)$ & 1 & 0.63 & 0.04 & 1 \\
\hline Biot's coefficient & 0 & 0 & 0.75 & 0 & 0 & 0.75 \\
\hline \multicolumn{7}{|l|}{ Mechanical properties } \\
\hline$E: M P a$ & 18 & 18 & $8000 / 3000 * *$ & 24 & $3.30 \times 10^{4}$ & $3.00 \times 10^{3}$ \\
\hline$v$ & $0 \cdot 35$ & 0.35 & $0 \cdot 33 / 0 \cdot 29 * *$ & $0 \cdot 2$ & $0 \cdot 3$ & $0 \cdot 29$ \\
\hline G: MPa & - & - & $3225 / 1000 * *$ & - & - & - \\
\hline \multicolumn{7}{|l|}{ Diffusivity } \\
\hline$f_{\mathrm{TV}}: \mathrm{m}^{2} / \mathrm{s}$ & Figure 3 & Figure 3 & & 3 & 3 & \\
\hline$\tau$ & 0.5 & 0.5 & & 0.5 & 0.5 & \\
\hline$\chi_{\mathrm{p}}: \mathrm{Pa}^{-1}$ & $1.00 \times 10^{-7}$ & $7 \cdot 50 \times 10^{-8}$ & $1 \times 10^{-9}$ & $7.50 \times 10^{-8}$ & $6 \times 10^{-10}$ & $1 \times 10^{-9}$ \\
\hline \multicolumn{7}{|l|}{ Brooks-Corey } \\
\hline$\alpha_{w}: m^{-1}$ & $8.92 \times 10^{-3}$ & $5.00 \times 10^{-3}$ & & & & \\
\hline$n$ & 0.55 & $0 \cdot 36$ & & & & \\
\hline 1 & $-1 \cdot 370$ & $5 \cdot 500$ & & & & \\
\hline \multicolumn{7}{|l|}{ van Genuchten } \\
\hline$\alpha_{w}: m^{-1}$ & & & $5.5 \times 10^{-4}$ & $5.0 \times 10^{-3}$ & $6.0 \times 10^{-04}$ & $2 \times 10^{-3}$ \\
\hline$n$ & & & 1.67 & 1.67 & 1.67 & 1.67 \\
\hline 1 & & & 2 & 2 & 2 & 2 \\
\hline \multicolumn{7}{|l|}{ Thermal properties } \\
\hline Thermal expansion $T_{\mathrm{x}}: \mathrm{K}^{-1}$ & $2.50 \times 10^{-5}$ & $2.50 \times 10^{-5}$ & $1.7 \times 10^{-5}$ & $1.7 \times 10^{-5}$ & $1.5 \times 10^{-5}$ & $1.7 \times 10^{-05}$ \\
\hline Thermal conductivity wet: W/(m K) & $1 \cdot 30$ & $1 \cdot 30$ & $1 \cdot 77 / 0 \cdot 98^{* *}$ & 1.9 & $1 \cdot 4$ & 1.96 \\
\hline Thermal conductivity dry: $\mathrm{W} /(\mathrm{m} \mathrm{K})$ & $0 \cdot 35$ & $0 \cdot 35$ & - & $1 \cdot 3$ & 0.5 & - \\
\hline Specific heat: $\mathrm{J} /(\mathrm{kg} \mathrm{K})$ & $800-1500$ & $800-1500$ & $946 \cdot 5$ & 995 & 1000 & $946 \cdot 5$ \\
\hline \multicolumn{7}{|l|}{ Initial conditions } \\
\hline Initial pore pressure: $\mathrm{Pa}$ & $-9.3 \times 10^{7}$ & $-1.25 \times 10^{8}$ & $1 \times 10^{6}$ & $-9 \cdot 3 \times 10^{7}$ & $-9 \cdot 3 \times 10^{7}$ & $1 \times 10^{6}$ \\
\hline
\end{tabular}

For Opalinus Clay, the parameters marked ' $* *$ ' indicate anisotropy in terms of the component parallel to bedding/component perpendicular to bedding

view of the filled tunnel is shown in Figure 6(b). The tube-like feature surrounding the EBS is a thin layer of excavation-induced damage zone (EDZ) with a radial thickness of $60 \mathrm{~cm}$ that is equivalent to the radius of the excavated tunnel. The EDZ around the tunnel is dependent on the stress condition and fabric structure, would likely be non-uniform in shape and possess anisotropic mechanical and hydraulic properties. However, the EDZ was not thoroughly characterised; therefore, for simplicity, the authors assumed its characteristics to be uniform and isotropic. The host rock outside the EDZ was thoroughly characterised. It is inherently anisotropic due to the bedding orientation; therefore, anisotropic hydraulic and mechanical properties as shown in Table 1 were used. The trace of the bedding plane is perpendicular to the microtunnel axis and dips with an angle of $40^{\circ}$ towards the south (Figure 6(c)).

The in situ stress was estimated as (Gaus et al., 2014)

$$
\begin{aligned}
& \sigma_{x}=-2 \cdot 2 \mathrm{MPa} \\
& \sigma_{y}=-4.3 \mathrm{MPa}
\end{aligned}
$$

14. $\sigma_{z}=-6 \cdot 5 \mathrm{MPa}$
The initial temperature and pore pressure in the rock are $15 \cdot 75^{\circ} \mathrm{C}$ and $1 \mathrm{MPa}$, respectively. The boundary conditions include fixed temperature and pore pressure for the outer boundaries. The left boundary (i.e. $x=0$ ) is a symmetrical boundary for all THM processes (i.e. zero water and heat flux and zero normal displacement).

\section{Modelling strategy for field scale tests}

The modelling replicates the three phases of the experimental test sequence: excavation followed by partial desaturation (10 years), emplacement ( $70 \mathrm{~d})$ and heating (3 years).

- Excavation and partial desaturation: To mimic excavation, the boundary load on the tunnel surface that is in equilibrium with the in situ stress was gradually removed. Pore pressure on the tunnel surface was reduced from the initial pore pressure to a suction value equivalent to $R_{\mathrm{H}}=95 \%$.

- Emplacement: The elements for the EBS were activated in this step to simulate the emplacement inside the tunnel. The EBS was emplaced with varying initial degrees of saturation, with corresponding suction as shown in Table 1. This suction in the EBS would withdraw water from the rock, and the redistribution of pore pressure and suction after the EBS 


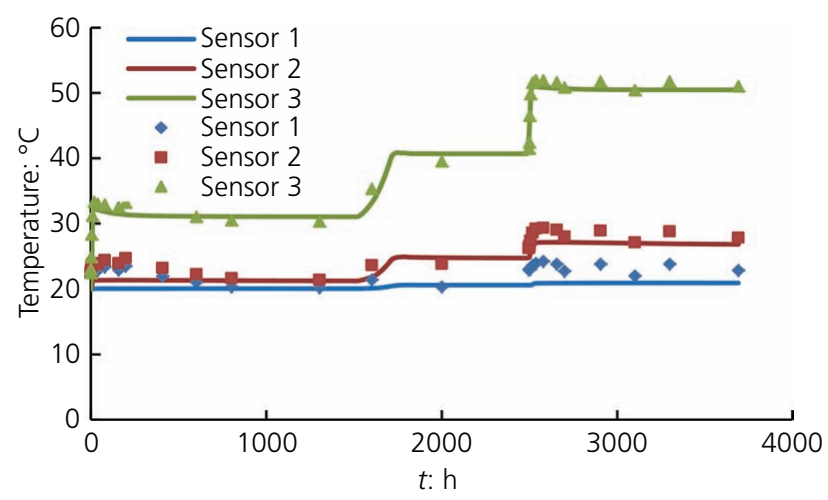

(a)

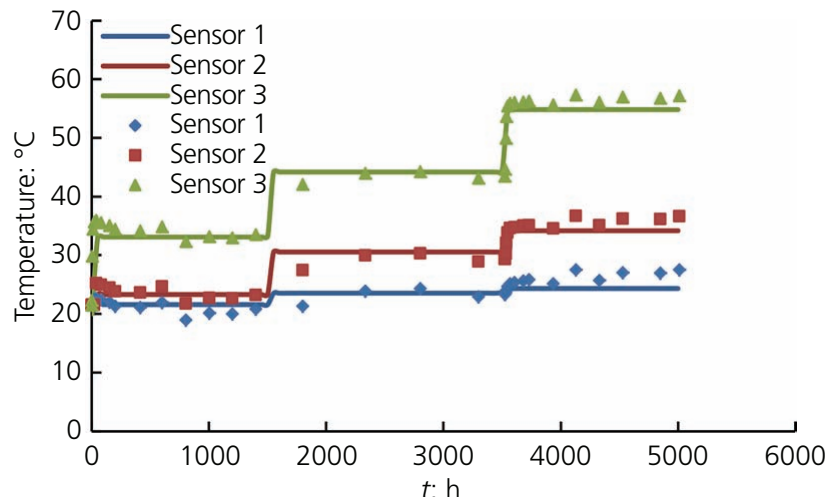

(c)

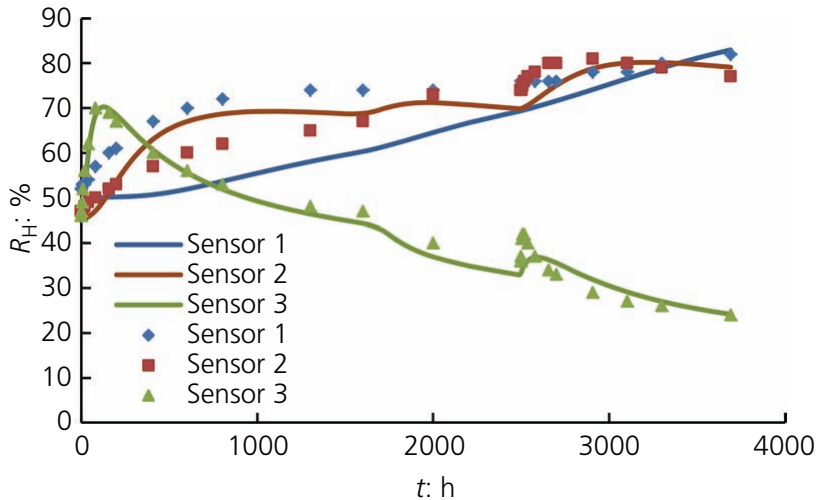

(b)

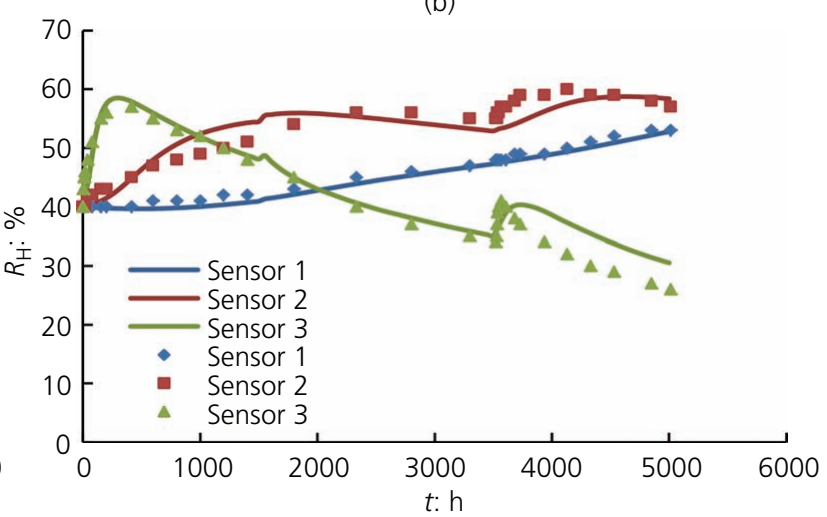

(d)

Figure 5. Comparison of modelled and test results of (a) temperature in $\mathrm{S} / \mathrm{B},(\mathrm{b}) R_{\mathrm{H}}$ in $\mathrm{S} / \mathrm{B},(\mathrm{c})$ temperature in $\mathrm{B}$ and (d) $R_{\mathrm{H}}$ in $\mathrm{B}$ (scattered diamonds, squares and triangles are test data and the solid lines are modelling results)

emplacement must be calculated in order to establish the initial conditions for the heating phase.

- Heating: In this stage, heat was supplied from the heaters. The boundary condition for the heater-EBS interface was described by thermal fluxes corresponding to the actual power supply (Gaus et al., 2014). The evolution of key variables such as relative humidity, temperature and pressure were continuously recorded at many monitoring points. The analysed heating periods consisted of $960 \mathrm{~d}$ until January 2014.

The simulation was also extended into long-term resaturation (11 000 years). The heating power was hypothesised to be shut down after a certain period of time ( 8 years in this study). The long-term evolution of moisture and temperature during the cooling period was predicted up to the time when full resaturation is achieved.

\section{Results and interpretation}

\section{Monitoring points}

In the HE-E test, extensive monitoring of temperature (T), pressure $(P)$ and relative humidity $\left(R_{\mathrm{H}}\right)$ was conducted in both the EBS and the host rock during the heating period. Figure 7 shows the location of temperature and humidity sensors placed inside the EBS materials as well as the convention of the nomenclature. For each EBS section, three cross-sections were designed for monitoring purposes. Only the one located in the centre of the EBS section was used in this study for comparison with the modelling results.

\section{Comparison between modelling results and test data Temperature data for S/B}

Figure 8 shows the evolution of temperature at the monitoring sensors inside the $\mathrm{S} / \mathrm{B}$. The experimental results are well reproduced by the model. The temperature at the central position (T-C) is somewhat overpredicted, the one in the middle (T-M) is somewhat underpredicted; however, excellent agreement is found for the point at the interface (T-H) between the EBS and the host rock.

\section{Relative humidity data for S/B}

Figure 9 shows the evolution of $R_{\mathrm{H}}$ in the $\mathrm{S} / \mathrm{B}$ section. The modelling results are in good agreement with the experimental data for monitoring points at the EBS-host rock interface, the middle and the central position of the EBS. Note that the authors have modelled the excavation and desaturation stages prior to the emplacement of EBS into the tunnel. The results for these two previous stages of engineering practices are not shown here. Therefore, the simulated $R_{\mathrm{H}}$ at the rock-EBS interface $t=0$ is overestimated and appears discrepant from the observed data. This 


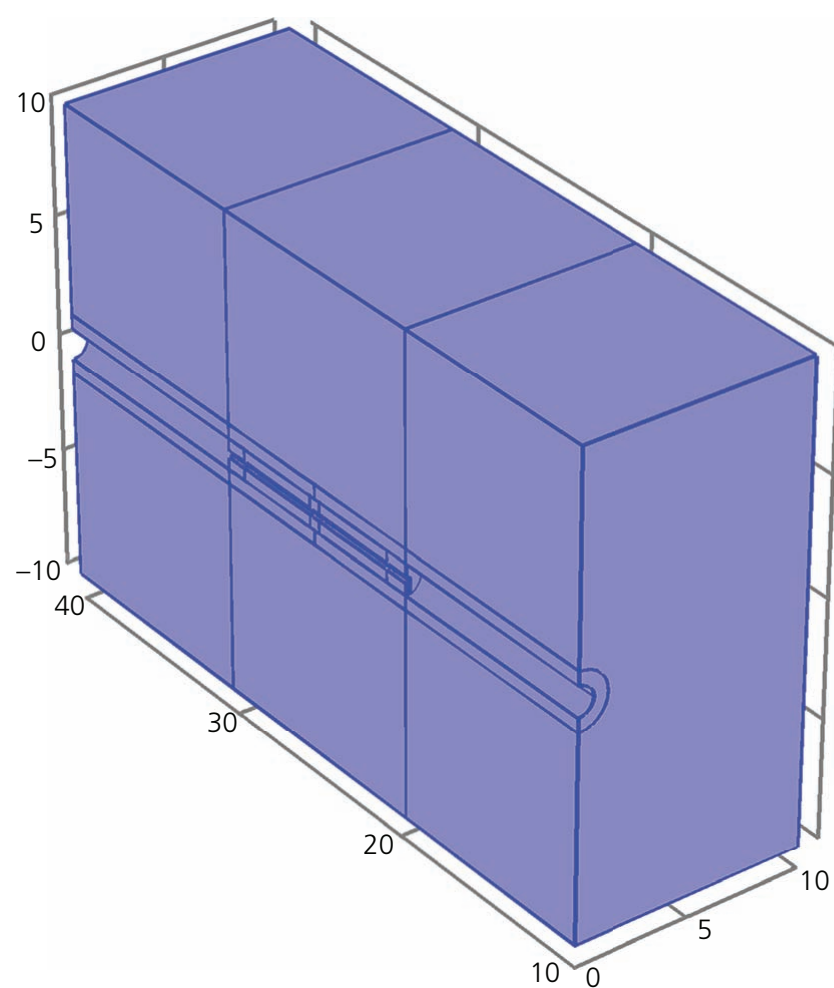

(a)

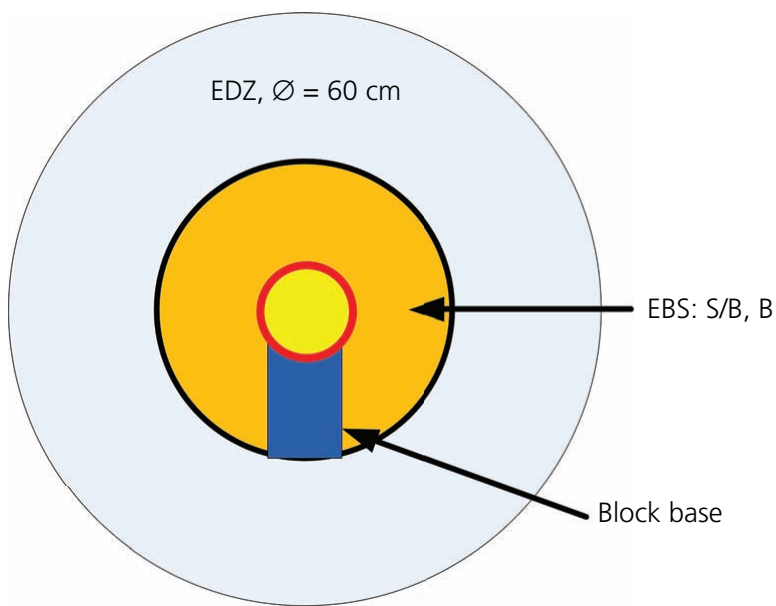

(b)

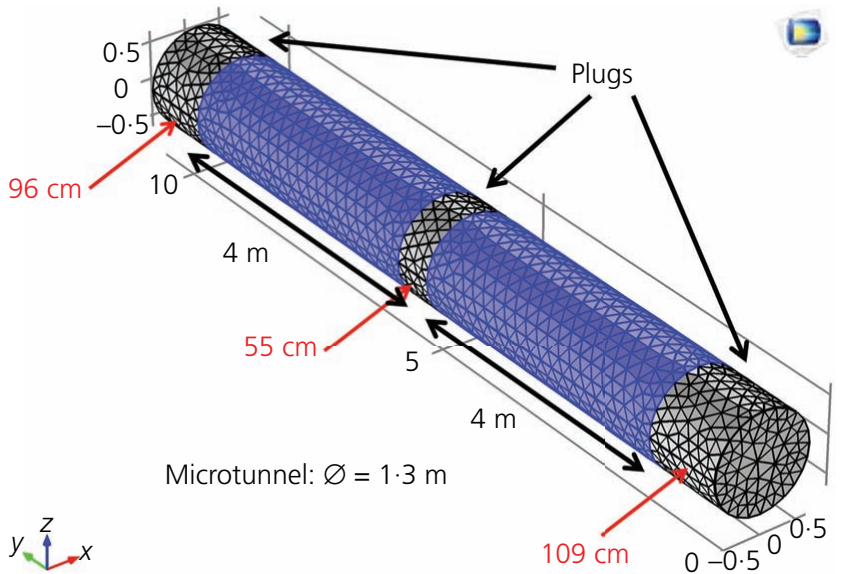

(c)

Figure 6. Schematic diagram showing the features of the FEM for the HE-E experiment: (a) the 3D geometry included in the model, (b) the microtunnel cross-section and (c) components

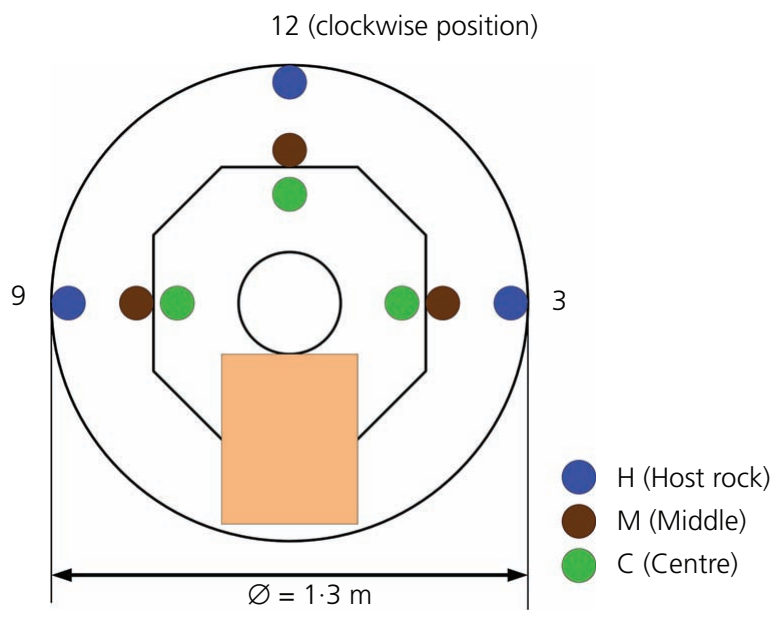

Figure 7. Location of temperature and relative humidity sensors installed inside EBS body for the field experiment

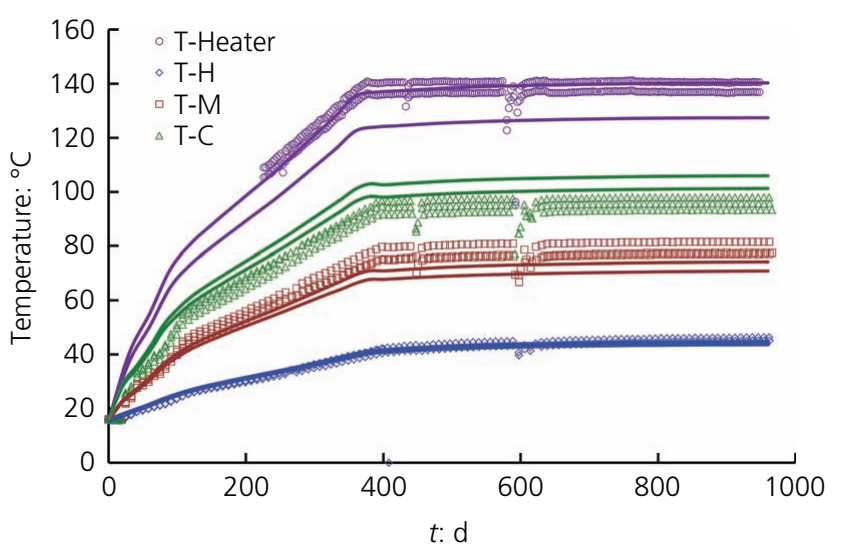

Figure 8. Temperature evolution for monitoring points inside the EBS at the S/B section (open symbols are test data and solid lines are modelling results). $\mathrm{T}-\mathrm{C}$, temperature at the central position; $\mathrm{T}-\mathrm{M}$, temperature at the middle position; $\mathrm{T}-\mathrm{H}$, temperature at the point at the interface 
Modelling a heater experiment for

radioactive waste disposal

Nguyen, Li, Garitte and Barnichon

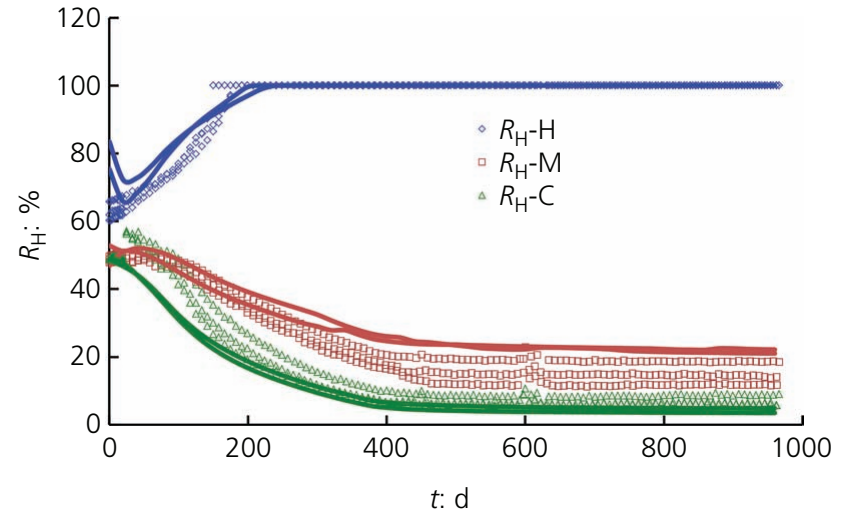

Figure 9. $R_{\mathrm{H}}$ comparison for EBS material in S/B section (open symbols are test data and solid lines are modelling results)

may be attributed to the higher estimation of permeability for the EDZ in the tunnel openings. However, the results of the following period of time give a high degree of agreement with test data.

\section{Temperature data for $\mathrm{B}$}

Figure 10 shows the evolution of temperature in the bentonite section. As with the S/B section, excellent agreement is found at the rock interface (T-H) with some discrepancy for the modelling results at the centre (T-C) and middle (T-M) points as compared to the test data. The heat transport process is closely coupled with moisture transport, through the dependence of the thermal conductivity and heat capacity on the effective saturation or moisture content. Therefore, the success in reproducing the moisture profile lays a good basis for best fitting of the temperature profile.

\section{Relative humidity data for $\mathrm{B}$}

Figure 11 shows the $R_{\mathrm{H}}$ evolution in the bentonite section. Similar to the case for $\mathrm{S} / \mathrm{B}$, good agreement is found for points at $\mathrm{H}, \mathrm{M}$ and $\mathrm{C}$ locations. Compared to the $\mathrm{S} / \mathrm{B}$ section, the $R_{\mathrm{H}}$ at $\mathrm{H}$ increases much more slowly in the $\mathrm{B}$ section. The resaturation of the

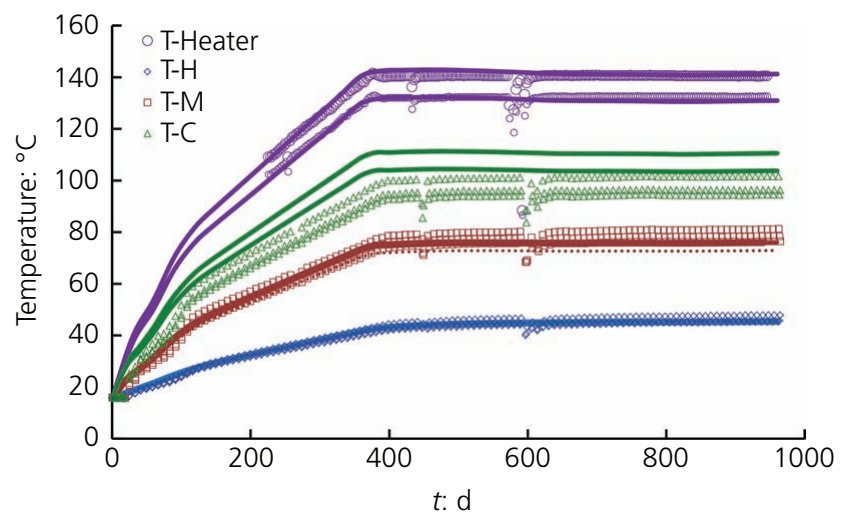

Figure 10. Temperature comparison for EBS material in the $\mathrm{B}$ section (open symbols are test data and solid lines are modelling results) bentonite near the rock interface is governed by two factors: vapour diffusion from the heat source and fluid infiltration from the surrounding host rock. Since vapour diffusivity characteristics are assumed to be the same for both types of EBS, the slower resaturation of the bentonite is mainly due to its lower permeability. Note that the initial decline of $R_{\mathrm{H}}$ for $R_{\mathrm{H}}-\mathrm{H}$ can be explained by the higher estimation of permeability for the EDZ around the tunnel opening, which resulted in faster water migration towards the EBS.

\section{THM coupling phenomena}

Figures 12(a)-12(c) show the time variation of $R_{\mathrm{H}}$ and temperature along representative profiles perpendicular to the tunnel axis, as shown in Figure 12(c). It is shown that heating induces a drying effect in the EBS near the heater surface. In the $\mathrm{S} / \mathrm{B}$, as shown in Figure 12(a), the $R_{\mathrm{H}}$ near the heater decreases to a value of 0.05 from an initial value of 0.5 . Heating induces outward vapour migration, leading to an increase in $R_{\mathrm{H}}$ in the EDZ domain. A steady-state distribution of $T$ and $R_{\mathrm{H}}$ seems to be reached after $400 \mathrm{~d}$.

Figure 12 is intended to show the dynamic evolution of critical parameters - that is, $R_{\mathrm{H}}$ and $T$ - in both EBS and host rock. This may reveal the effect of EBS and its thermal conductivity on the accumulated temperature on heater-EBS interface, which has a significant implication for the proper design of EBS in order to maintain a comparatively fast thermal conduction from spent fuel canister towards the host rock. Moreover, the evolution of $R_{\mathrm{H}}$ reflects the moisture movement, which is complex in view of the coupled influences of suction and thermal gradients. It is shown that the moisture of EDZ is partly attracted to EBS across the EBS-EDZ interface prior to the start of the heating. But this process turns out to be reversed by the heating. Thermal gradient prevails over suction gradient regarding moisture migration in EBS-EDZ zones.

As shown in Figure 12(b), the heater surface reaches a maximum temperature of about $140^{\circ} \mathrm{C}$, while the maximum temperature in the rock is less than $46^{\circ} \mathrm{C}$ (an increase of $30^{\circ} \mathrm{C}$ from the background). The temperature increase results in the thermal

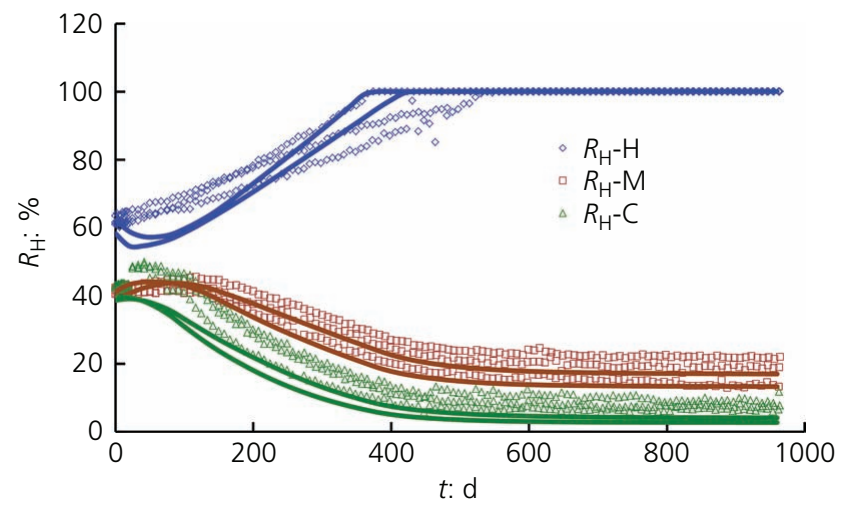

Figure 11. $R_{\mathrm{H}}$ comparison for EBS material in $\mathrm{B}$ section (open symbols are test data and solid lines are modelling results) 


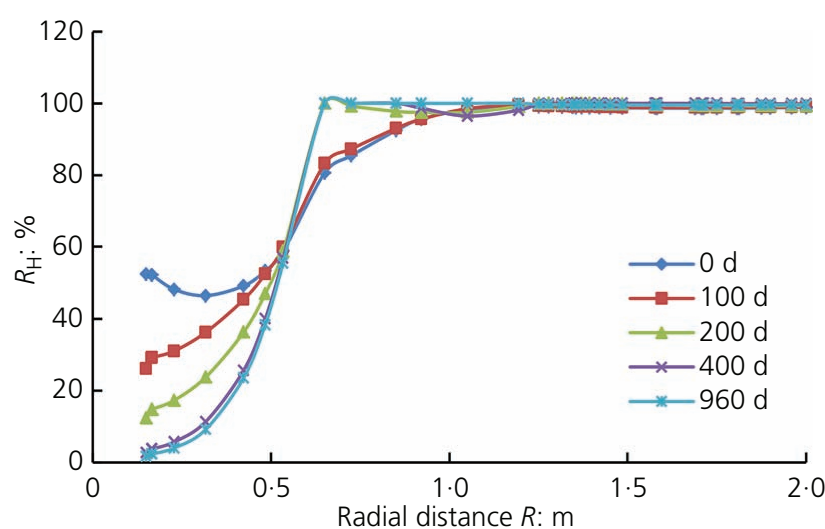

(a)

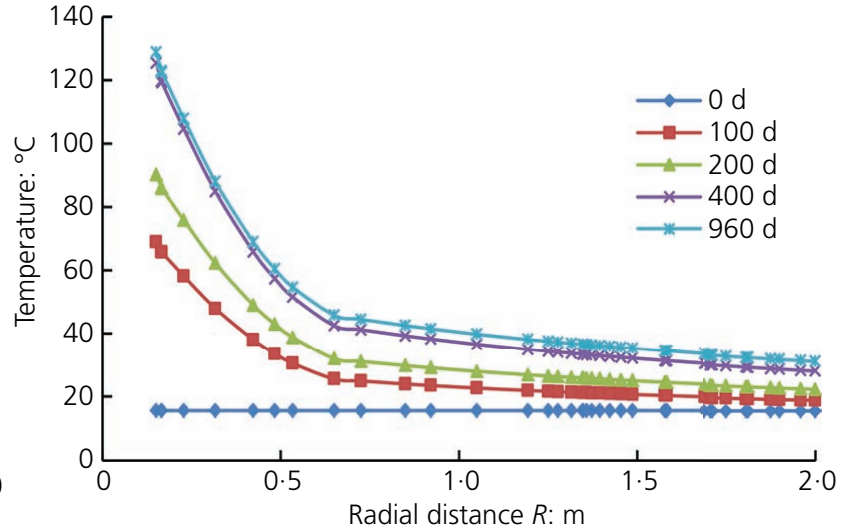

(b)

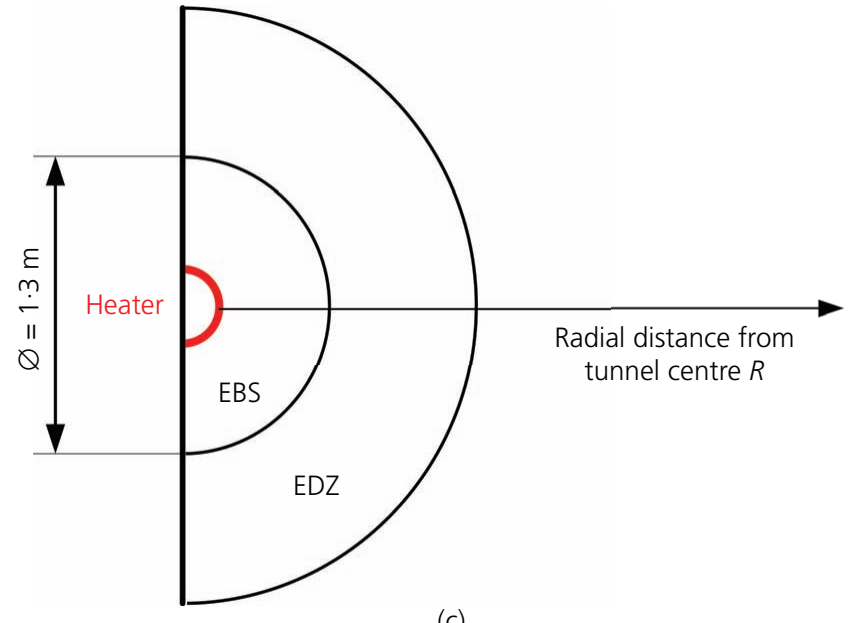

(c)

Figure 12. Distribution of various variables $(a, b)$ along the horizontal cut line across the centre of S/B section (c)

expansion of the pore water and of the solid skeleton. Due to confinement, thermal expansion is constrained, resulting in the pore water pressure increase near the heat source that gradually dissipates when outward drainage from the heat source progressively takes place. The calculated and measured pore pressure increases at several points in the rock are shown in Figure 13(a). It is shown that the model can reproduce the trends of the pore pressure evolution. The thermally induced pore pressure results from a full coupling of THM processes. In particular, the permeability of the rock and its stress-strain behaviour (as reflected in the value of the Young's modulus if elasticity is assumed) significantly influence the absolute value and the dissipation rate of the pore pressure (Gens et al., 2007; Selvadurai and Nguyen, 1997). The model underestimated the maximum pore pressure by $30 \%$. One plausible reason for this discrepancy could be the assumption of homogeneity adopted in the model. Opalinus Clay is not perfectly homogeneous, and variations in some of the key parameters discussed earlier can result in significant variations in the pore pressure. In addition, extra swelling pressure can be induced by the increasing saturation of the bentonite at the rock interface. The difference between the observed and the predicted maximum pore pressure could also be attributed to the volumetric swelling of the EBS, which imposed an additional load on the saturated host rock, but was omitted in the present model. In this regard, more sophisticated constitutive models that take into account the swelling of the EBS are being developed by the authors. A thermally induced pore pressure can induce hydrofracturing, when it exceeds the minimum principal stress. In the HE-E experiment, because of the relatively low temperature increase in the rock, the maximum pore pressure reached a value of approximately $1 \mathrm{MPa}$, while the minimum principal stress is in the $2-3 \mathrm{MPa}$ range. Therefore, hydrofracturing would be unlikely in this particular case.

\section{Long-term resaturation estimation}

Figures 14(a) and 14(b) show the modelling results of the long-term resaturation process that follows immediately the shutdown of the heating source at 7.9 years. It is shown clearly that the temperature profile in the EBS declines rapidly to the background level at $15 \cdot 75^{\circ} \mathrm{C}$. The moisture level quickly becomes equilibrated at $R_{\mathrm{H}}=$ $41 \%$ within 20 years of post-closure. Since the temperature gradient diminishes, moisture migration may only be dominated by the pressure gradient according to Equations 4 and 5. The resaturation is 


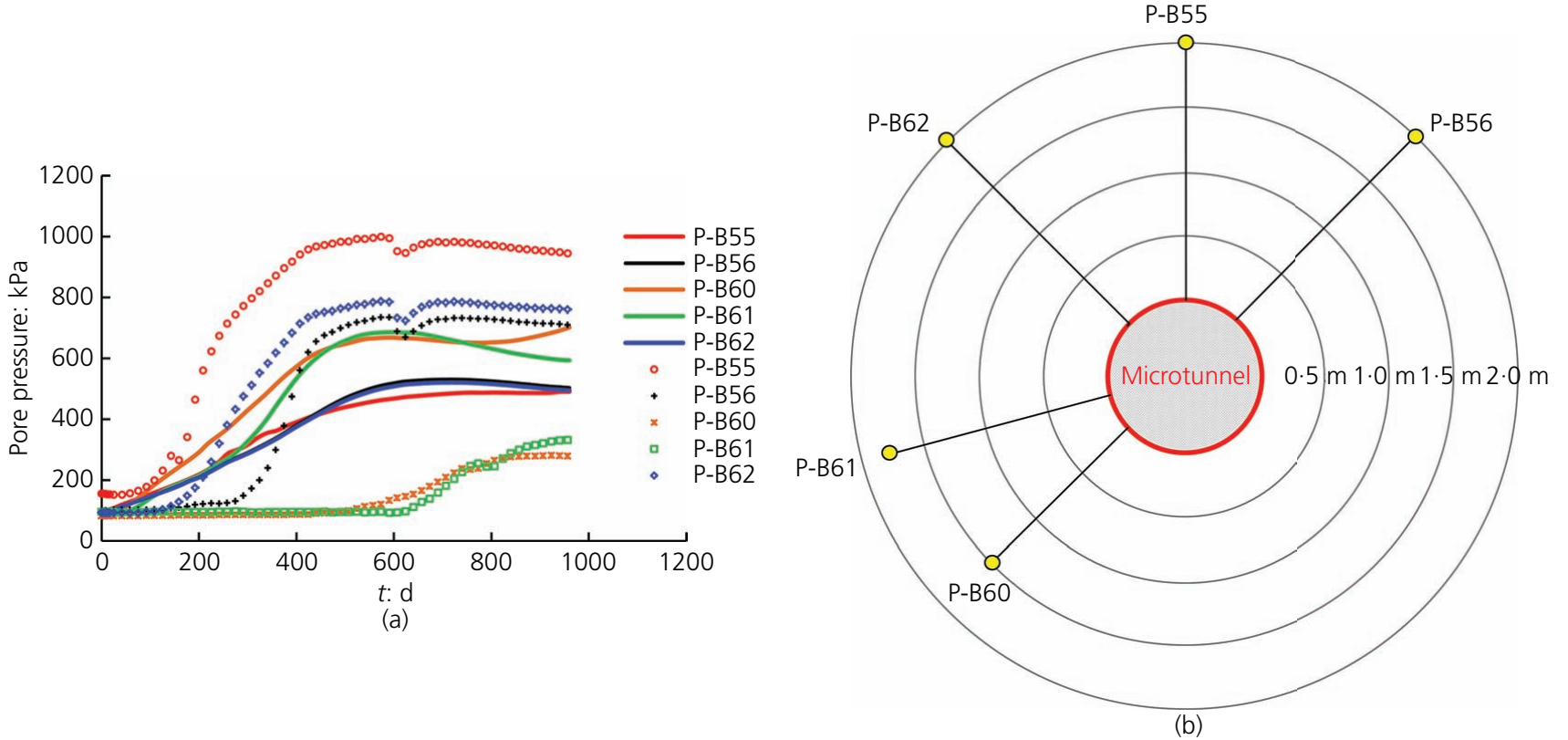

Figure 13. (a) Thermally induced pore pressure in the host rock at the midplane cross-section of B section for various locations and (b) the sensor arrangement in space (marked distance with respect to microtunnel wall)

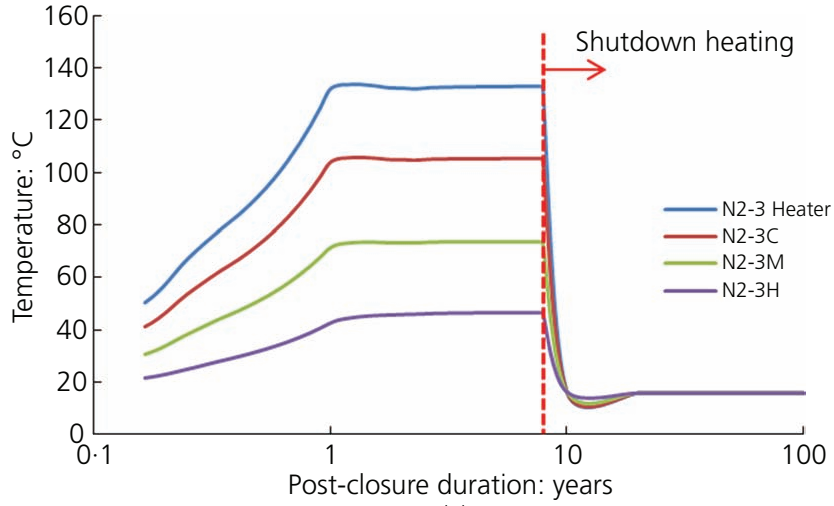

(a)

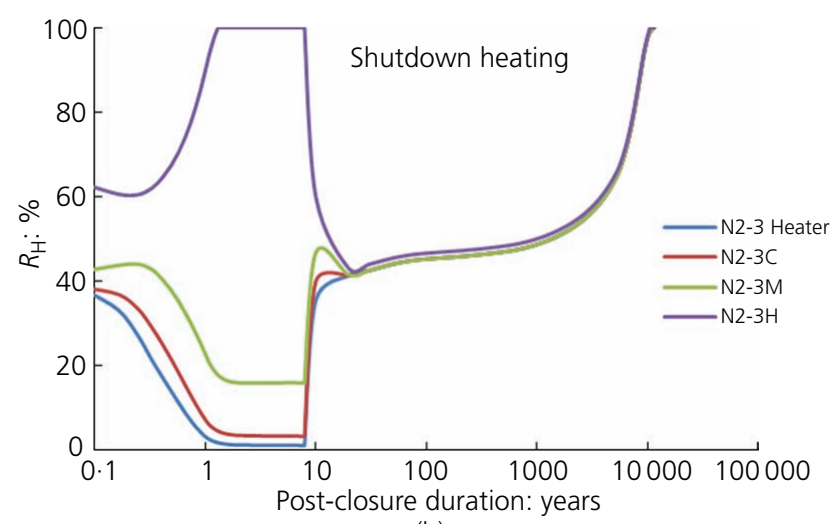

(b)

Figure 14. Evolution of (a) temperature and (b) relative humidity in the long-term period along the radial direction for section N2 at the '3 o'clock' location

governed by the host rock as the source of pore fluid in the longterm period. The model predicts that complete saturation (>99.99\%) of the EBS would be achieved in 11000 years.

\section{Discussion}

In many concepts of geological disposal, the main safety functions of the EBS are to protect the waste container by

- providing mechanical support

- reducing microbial activity in order to control corrosion

- limiting the rate of groundwater flow in its vicinity

- dissipating heat from the container.
The swelling potential, the permeability and the thermal properties of the EBS are important indicators for its ability to achieve the safety functions mentioned earlier. Those properties depend on the saturation of the EBS. The drying effects due to heating decrease the thermal conductivity and can result in higher temperatures in the EBS. Heating also can delay the resaturation of the EBS (Millard et al., 2005) and therefore hinders its swelling potential, for a transient period of time. The resaturation time of the EBS also depends on the permeability of the host rock and its capability to supply water to the EBS. The thermally induced pore pressure in the rock can potentially induce hydrofracturing if the pore pressure exceeds the minimum principal stresses. Hydrofracturing was not the case for the HE-E 
experiment; however, it should be verified for each specific situation. The engineering design and safety assessment of geological disposal systems should take into account relevant coupled THM processes such as the ones discussed in this paper, depending on the specific design and site conditions. Such a consideration can only be reliably performed with the use of THM modelling tools that are extensively verified and calibrated with experimental data.

\section{Conclusions}

The HE-E experiment performed at the Mont Terri Rock Laboratory represents a half-scale model of two waste containers/ EBS units of the Swiss geological disposal concept. The monitoring data collected during the experiment are invaluable for the understanding of the near-field coupled THM processes in the EBS and near-field rock and for the development of mathematical models to interpret those processes. In this work, the authors have developed a mathematical model that can reasonably simulate the main features of the coupled THM processes, both in trends and absolute values, in particular with respect to the following points.

Heating induces outward vapour migration from the heat source. This results in the drying of the EBS in the vicinity of the heat source. In the test, this drying effect is generalised in the EBS, except at points near the rock interface, where resaturation occurs. The water that is supplied to those points comes from two sources: infiltration from the host rock and condensation of vapour originating from the hotter part of the EBS.

Drying in the EBS results in a decrease of its thermal conductivity, leading to higher temperatures. In the HE-E experiment, maximum temperatures of $140^{\circ} \mathrm{C}$ were applied at the heater surface, while in the rock, they are limited to $46^{\circ} \mathrm{C}$ after $900 \mathrm{~d}$ of heating.

In the rock, the pore water pressure increases due to its tendency for thermal expansion. The absolute value for this increase depends on the permeability and stiffness of the rock. The pressures would be higher for lower permeability and higher stiffness. In the HE-E experiment, the recorded pressure was lower than $1 \mathrm{MPa}$, and the calculated pressure was of the same order of magnitude.

Resaturation of the EBS is estimated to take at least 11000 years before reaching full saturation $(>99 \%)$ in a shutdown of the heating source following 8 years of maintaining a constant temperature of $140^{\circ} \mathrm{C}$ on the heater-EBS interface. This long resaturation time is consistent with previous findings (Millard et al., 2005) and is found when the host rock is unfractured and has very low permeability. Should such a long resaturation time be found to be associated with a geological disposal system, the implications on the repository performance should be assessed.

\section{Acknowledgements}

This study has been funded by the Canadian Nuclear Safety Commission. The HE-E experiment has received funding from the
European Atomic Energy Community's Seventh Framework Programme (FP7/2007-2011) under grant agreement 249681. Participants in the Decovalex project are also thanked for the many helpful discussions and peer review during the course of this work. Colleagues at the Canadian Nuclear Safety Commission, Dr P. Thompson, Mr A. McAllister and Mr P. Button, are also sincerely thanked for their careful review of this study.

\section{REFERENCES}

Cass A, Campbell GS and Jones TL (1984) Enhancement of thermal water vapor diffusion in soil. Soil Science Society of America Journal 48(1): 25-32, http://dx.doi.org/10.2136/sssaj1984.03615995004800010005x.

Chijimatsu M, Fujita T, Kobayashi A and Nakano M (2000) Experiment and validation of numerical simulation of coupled thermal, hydraulic and mechanical behaviour in the engineered buffer materials. International Journal for Numerical and Analytical Methods in Geomechanics 24(4): 403-424, http://dx.doi.org/10.1002/(SICI)10969853(20000410)24:4

Chijimatsu M, Borgesson L, Fujita T et al. (2009) Model development and calibration for the coupled thermal, hydraulic and mechanical phenomena of the bentonite. Environmental Geology 57(6): 1255-1261, http://dx.doi.org/10.1007/s00254-008-1401-2.

Cho WJ, Lee JO and Kwon S (2009) Simulation of heat and water counterflow in unsaturated compacted bentonite. Environmental Engineering Science 26(3): 589-599, http://dx.doi.org/10.1089/ ees.2007.0357.

Decovalex (2017) http://www.decovalex.org (accessed 06/03/2017).

Gaus I, Wieczorek K, Schuster K et al. (2014) EBS Behaviour Immediately after Repository Closure in a Clay Host Rock: HE-E Experiment (Mont Terri URL). Geological Society, London, UK, Special Publications 400.

Gens A, Vaunat J, Garitte B and Wileveau Y (2007) In situ behaviour of a stiff layered clay subject to thermal loading: observations and interpretation. Géotechnique 57(2): 207-228, http://dx.doi.org/ 10.1680/geot.2007.57.2.207.

Gens A, Sanchez M, Guimaraes LD et al. (2009) A full-scale in situ heating test for high-level nuclear waste disposal: observations, analysis and interpretation. Géotechnique 59(4): 377-399, http://dx. doi.org/10.1680/geot.2009.59.4.377.

Hökmark H, Ledesma A, Lassabatere T et al. (2007) Modelling heat and moisture transport in the ANDRA/SKB temperature buffer test. Physics and Chemistry of the Earth, Parts A/B/C 32(8-14): 753-766, http://dx.doi.org/10.1016/j.pce.2006.04.024.

Holton D, Baxter S and Hoch AR (2012) Modelling coupled processes in bentonite: recent results from the UK's contribution to the Aspo EBS Task Force. Mineralogical Magazine, December: pp. 3033-3043.

Kröhn KP (2005) New evidence for the dominance of vapour diffusion during the re-saturation of compacted bentonite. Engineering Geology 82(2): 127-132, http://dx.doi.org/10.1016/j.enggeo.2005.09.015.

Kröhn KP (2010) Simulating non-isothermal water uptake of compacted bentonite without coupling of hydraulics to mechanics. Applied Clay Science 47(1-2): 28-35, http://dx.doi.org/10.1016/j.clay.2008. 06.004.

Massart TJ and Selvadurai APS (2014) Computational modelling of crack-induced permeability evolution in granite with dilatant cracks. International Journal of Rock Mechanics and Mining Sciences 70: 593-604, http://dx.doi.org/10.1016/j.ijrmms.2014.06.006.

Millard A, Rejeb A, Chijimatsu M et al. (2005) Numerical study of the THM effects on the near-field safety of a hypothetical nuclear waste repository - BMT1 of the DECOVALEX III project: part 2: effects of THM coupling in continuous and homogeneous rocks. International Journal of Rock Mechanics and Mining Sciences 42(5-6): 731-744, http://dx.doi.org/10.1016/j.ijrmms.2005.03.011. 
Modelling a heater experiment for

radioactive waste disposal

Nguyen, Li, Garitte and Barnichon
Nguyen TS and Selvadurai APS (1995) Coupled thermal-mechanicalhydrological behavior of sparsely fractured rock - implications for nuclear fuel waste disposal. International Journal of Rock Mechanics and Mining Sciences and Geomechanics Abstracts 32(5): 465-479, http://dx.doi.org/10.1016/0148-9062(95)00036-G.

Nguyen TS and Selvadurai APS (1997) Coupled thermal-hydraulicmechanical processes in a cylindrical cavity in rock. In NUMOG VI: Proceedings of the International Symposium on Numerical Models in Geomechanics (Pande GN and Pietruszczak S (eds)). AA Balkema, Leiden, the Netherlands, pp. 315-324.

Nguyen TS, Selvadurai APS and Armand G (2005) Modelling the FEBEX THM experiment using a state surface approach. International Journal of Rock Mechanics and Mining Sciences 42(5-6): 639-651, http://dx. doi.org/10.1016/j.ijrmms.2005.03.005.

Philip JR and De Vries DA (1957) Moisture movement in porous materials under temperature gradients. Eos, Transactions American Geophysical Union 38(2): 222-232, http://dx.doi.org/10.1029/TR038i002p00222.

Pintado X, Autio J and Punkkinen O (2011) On the behaviour of compacted bentonite under thermal gradients. Physics and Chemistry of the Earth 36(17-18): 1799-1805, http://dx.doi.org/10.1016/j.pce. 2011.10.004

Rutqvist J, Borgesson L, Chijimatsu M et al. (2001) Thermohydromechanics of partially saturated geological media: governing equations and formulation of four finite element models. International Journal of Rock Mechanics and Mining Sciences 38(1): 105-128, http://dx.doi.org/10. 1016/S1365-1609(00)00068-X

Rutqvist J, Barr D, Datta R et al. (2005a) Coupled

thermal-hydrological-mechanical analyses of the Yucca Mountain Drift scale test - comparison of field measurements to predictions of four different numerical models. International Journal of Rock Mechanics and Mining Sciences 42(5-6): 680-697, http://dx.doi.org/ 10.1016/j.ijrmms.2005.03.008.

Rutqvist J, Chijimatsu M, Jing L et al. (2005b) A numerical study of THM effects on the near-field safety of a hypothetical nuclear waste repository - BMT1 of the DECOVALEX III project: part 3: effects of THM coupling in sparsely fractured rocks. International Journal of Rock Mechanics and Mining Sciences 42(5-6): 745-755, http://dx.doi org/10.1016/j.ijrmms.2005.03.012.
Rutqvist J, Zheng L, Chen F, Liu HH and Birkholzer J (2014) Modeling of coupled thermo-hydro-mechanical processes with links to geochemistry associated with bentonite-backfilled repository tunnels in clay formations. Rock Mechanics and Rock Engineering 47(1): 167-186, http://dx.doi.org/10.1007/s00603-013-0375-x.

Schanz T, Long NT and Datcheva M (2013) A column experiment to study the thermo-hydro-mechanical behaviour of expansive soils. Rock Mechanics and Rock Engineering 46(6): 1287-1301, http://dx.doi.org/ 10.1007/s00603-012-0361-8.

Selvadurai APS (1996) Heat-induced moisture movement in a clay barrier: 2. Computational modelling and comparison with experimental results. Engineering Geology 41(1-4): 219-238, http://dx.doi.org/10.1016/ 0013-7952(96)84603-5.

Selvadurai APS (2002) Influence of pressurized water influx on the hygrothermal behaviour of an engineered clay barrier in a waste emplacement borehole. Engineering Geology 64(2-3): 157-178, http:// dx.doi.org/10.1016/S0013-7952(01)00105-3.

Selvadurai APS (2015) Normal stress-induced permeability hysteresis of a fracture in a granite cylinder. Geofluids 15(1-2): 37-47, http://dx.doi. org/10.1111/gfl.12107.

Selvadurai APS and Nguyen TS (1997) Scoping analyses of the coupled thermal-hydrological-mechanical behaviour of the rock mass around a nuclear fuel waste repository. Engineering Geology 47(4): 379-400, http://dx.doi.org/10.1016/S0013-7952(96)00100-7.

Thomas HR, Vardon PJ and Cleall PJ (2014) Three-dimensional behaviour of a prototype radioactive waste repository in fractured granitic rock. Canadian Geotechnical Journal 51(3): 246-259, http://dx.doi.org/10. 1139/cgj-2013-0094.

Villar MV and Lloret A (2004) Influence of temperature on the hydromechanical behaviour of a compacted bentonite. Applied Clay Science 26(1-4): 337-350, http://dx.doi.org/10.1016/j.clay.2003.12.026.

Villar MV, Martín MV, Gómez-Espina R, Romero FJ and Barcala JM (2012) Long-term THM Tests Reports: THM Cells for the HE-E Test: Setup and First Results. Ciemat, Madrid, Spain, Report Ciemat/DMA/2G210/03.

Zheng LG, Samper J, Montenegro L and Fernandez AM (2010) A coupled THMC model of a heating and hydration laboratory experiment in unsaturated compacted FEBEX bentonite. Journal of Hydrology 386(1-4): 80-94, http://dx.doi.org/10.1016/j.jhydrol.2010.03.009.

\section{How can you contribute?}

To discuss this paper, please submit up to 500 words to the editor at journals@ice.org.uk. Your contribution will be forwarded to the author(s) for a reply and, if considered appropriate by the editorial board, it will be published as a discussion in a future issue of the journal. 